\title{
De Inkarrí a guerrillero: Imagen visual y figura del heroico caminante andino
}

Luis Rebaza Soraluz

King's College, University of London

El objetivo general de este ensayo es discutir en imágenes y textos selectos algunas ideas que se propusieron en el Perú a mediados del siglo XX sobre el papel de lo andino en la nación moderna. El objetivo particular es estudiar representaciones visuales de Luis Montero, Felipe Guamán Poma de Ayala y Fernando de Szyszlo, centradas en el fin del incanato, y textos de Ricardo Palma, José María Arguedas, José Lezama Lima, entre otros, que postulan ideas acerca de la historia como continuidad no lineal, narrativas culturales alternativas a la histórica, e incluyen la figura mítica y continental del heroico caminante andino, protagonista de una gesta que amalgama los relatos de Inkarrí y la biografía del Che Guevara.

\section{Arguedas, Atahualpa, cultura andina, Che Guevara, Guamán Poma, Inkarrí, mesianismo, Montero, Palma, pintura abstracta, Szyszlo.}

\section{From Inkarri to Guerrilla Fighter: Visual Image and Figure of the Heroic Andean Wandering Walker}

The general objective of this essay is to discuss in selected images and texts some ideas on the role of the Andean in the modern nation that arose in mid-20th century Peru. Its particular objective is to study visual representations centred on the end of Inca rule, produced by Luis Montero, Felipe Guamán Poma de Ayala and Fernando de Szyszlo, and on texts by Ricardo Palma, José María Arguedas, José Lezama Lima, among others, that include statements regarding ideas of History as a non-lineal continuity, cultural narratives as alternatives to historical accounts, and the mythical and continental figure of the Heroic Andean Wandering Walker, protagonist of a saga that amalgamates the Inkarrítales and Che Guevara's biography.

Andean cultura, Arguedas, Atahualpa, Abstract painting, Che Guevara, Guamán Poma, Inkarrí, messianism, Montero, Palma, Szyszlo.

A inicios de la década de 1960, Fernando de Szyszlo produjo dos series de pinturas abstractas con títulos en quechua y el tema común de la muerte del último Inca: Cajamarca (1962) y Apu Inca Atawallpaman (1963). Como proyecto nacional, su antecedente pictórico más notable era la pintura de gran formato Los funerales de Atahualpa (1863-1865) de Luis Montero. Teniendo en cuenta la importancia y gran visibilidad pública que obtuvo este último cuadro, en los sesenta la pintura de Szyszlo pudo haberse leído como una actualización del trabajo de Montero. El que Szyszlo produjera poco después dos series más con motivos semejantes, La ejecución de Túpac Amaru (1967) e Inkarrí (1968), abrió la posibilidad de que las cuatro series constituyeran un gran conjunto visual histórico. Presentar a Atahualpa, presentar luego la figura del último Inca de ascendencia directa y, seguidamente, un mito mesiánico, implicaba que Szyszlo no había representado el fin de lo andino 
como continuidad lineal, sino lo andino como presencia repetida y hasta como futuro. Su pintura no hacía referencia a los individuos Atahualpa y Túpac Amaru, ponía, más bien, énfasis en su estatus. Eliminar las particularidades mediante la yuxtaposición de una muerte (1533) a otra (1572), le permitió inicialmente a Szyszlo presentar como tema el destino del orden social representado por el Inca; yuxtaponerles, luego, la resurrección del Inka-Rey, le permitió dejar en claro que por "último" no debía entenderse "final" sino "más reciente". La producción en 1969 de la serie Valle Grande, dedicada a Ernesto Che Guevara, yuxtapuso la figura del guerrillero a la de los Incas mientras cuestionaba la historia como continuidad lineal en toda Latinoamérica.

Este ensayo explora en representaciones visuales clave algunas maneras de entender la historia como continuidad no lineal en el Perú del siglo XX, y analiza específicamente en la década del sesenta la construcción de una narrativa cultural de proyección mítica y alcance continental. Arguyo que las series históricas de Szyszlo no sólo dialogan con el cuadro de Montero de igual a igual sino que incluso se proponen competir por el lugar que la pintura había ocupado en la discusión nacional. Ambos parecen presentar interpretaciones opuestas de la historia. Montero declara el fin de un linaje indígena como una progresión inevitable, la alternativa andina como imposibilidad para la nación moderna, y la europeización como inicio de un proyecto político cultural que sigue leyes universales y científicas; los críticos del cuadro de Montero ${ }^{1}$ ven aquí una argumentación ideológica que sustenta el nacionalismo criollo liberal novecentista. Szyszlo sostiene que existe una resistencia indígena, que la nacionalidad andina se actualiza, y que la causalidad histórica no satisface el lado no racional de proyectos político culturales; los críticos de Szyszlo² encuentran en sus cuadros una ideología nacionalista de lenguaje internacional que afirma una posición de clase media enfrentada a la oligarquía y no una viable alternativa revolucionaria. Dentro de esta última propuesta, este ensayo discute cierto latinoamericanismo contemporáneo que se apoya en una historia recurrente encarnada en la figura de quien llamo "el heroico caminante andino".

La narrativa de Montero se sustenta en modelos de representación de lo americano que provienen tanto del discurso científico racial del siglo XIX, como de estructuras dramáticas del siglo XVIII presentes en textos e imágenes de lo que Deborah Poole llama la "Operática Inca". El cuadro de Montero, de riguroso academicismo histórico, refuerza su composición clásica con posturas teatrales y recursos ilusionistas que incluyen la proporción natural. Montero se vale además de la tipología fenotípica para la representación de lo indígena peruano ofreciendo al público contemporáneo una explicación razonada de la derrota indígena mediante la inclusión antropométrica de Atahualpa, el único cuerpo con rasgos físicos andinos de todos los personajes. Montero humaniza al divino Atahualpa representándolo sin idealizaciones; también confirma visualmente tanto su inferioridad racial y decadencia cultural como la correcta remoción de su estatus llevada a cabo por Pizarro.

La causalidad histórica de la narrativa de Montero, barbarie-civilización, revela sus bases en el discurso científico sobre la raza que naturalistas europeos a principios del siglo XIX habían elaborado al estudiar los orígenes lingüísticos de las lenguas americanas ligados a las características fisiológicas y morales de sus habitantes nativos. Juicios sobre la inferioridad de razas y civilizaciones americanas en comparación a Europa llevó al argentino Vicente Fidel López a escribir lo siguiente en una reseña de 1867 al cuadro de Montero:

1 Gustavo Buntinx. 2007. Lo impuro y lo contaminado: pulsiones (neo) barrocas en las rutas de MicroMuseo. Lima. Tarjeta para la Bienal de Sao Paulo-Valencia; Roberto Miró Quesada. 1983. "Los funerales de Atahualpa". El Caballo Rojo 13-11:10-11.; Gonzalo Portocarrero. 2009. Accesible en internet https://gonzaloportocarrero. lamula.pe/2009/09/17/disonancias-de-lo-criollo/gonzaloportocarrero/ [Consulta julio 30 de 2014 12:45 horas].

2 Mirko Lauer. 1977. Introducción a la pintura peruana del siglo XX. Lima: Mosca Azul Editores.; Castrillón 1980. 
Y allí, en ese lienzo, se halla escrito con una elocuencia sobrehumana para quien sabe comprenderlo, el consummatum est de la historia y de los tiempos antiguos: Ate, el Destino malo de los cánticos de Homero; Ate, el Agüero malo de los Amautas, cierne sus alas y levanta sus graznidos, como el Búho, sobre las mustias paredes de aquel templo, de aquel palacio en donde un día antes vivían en regia opulencia los últimos herederos de los Pharaones ${ }^{3}$.

Interesado como otros científicos de la época en los orígenes de las poblaciones a partir de la evolución de las lenguas, López se sirve de la narrativa de Montero para forzar una polémica alrededor de los posibles orígenes griegos de la lengua y cultura quechuas. Su simpatía hacia lo andino no descarta que López también entienda el fin del orden andino como algo consumado y sin retorno.

Las estructuras dramáticas de Montero, por su parte, tienen modelos románticos que se encuentran en obras como Alzire ou les Americains (1736), de Voltaire. Como bien señala Poole, Alzire presenta tres posiciones en tensión: la que sostiene una "conquista violenta y la conversión forzosa"; la que responde en oposición igual de intolerante y violenta pero justificada debido a "la extremada crueldad de los españoles"; y una que media con moderación y tolerancia proponiendo la "conversión religiosa pacífica y alianza política"". Las primeras posiciones son encarnadas por personajes varones, el conquistador y el Inca, y la tercera por el personaje femenino de la virginal princesa nativa. La tensión dramática en el cuadro de Montero parece creada mediante el antagonismo de dos fuerzas: los españoles y los andinos; sin embargo, se trata de un triángulo. Todos en el grupo indígena están en la posición de víctimas a pesar de haber diferencias visibles; en el grupo de españoles, sin embargo, hay dos posiciones morales: el fanatismo, de sacerdotes y soldados, y la contrastante templanza de Pizarro. En las obras dieciochescas lo indígena peruano encarnaba posiciones morales mediante encuentros físicos que indirectamente hacían alusión a circunstancias europeas; como sostiene Poole, en el encuentro entre la posición intransigente del conquistador y "la figura deseable aunque distante, similar aunque diferente, de la Virgen del Sol"5 al público europeo le eran revelados la diferencia y la razón. La diferencia entre estos mundos no era mostrada fenotípicamente, como lo será después, sino por posiciones morales, y por ello era aceptable el uso de idealizaciones clásicas. La tensión dramática en Alzire se resuelve cuando, en su intercambio físico con la superioridad moral del cuerpo femenino, el conquistador es expuesto a la razón y la sensatez. Para finales del siglo XVIII aparece un modelo dramático de Operática Inca en cuyo final se cancela la posibilidad de una resolución sensata y se deja como resultado la trágica desaparición del mundo andino. Este último tipo de tensión triangular y resolución se asemeja más al de Montero. En su cuadro, donde hubiese sido de esperar que se buscara que el espectador empatice y se alinee con las víctimas indígenas, en realidad se busca que el espectador adopte la posición de Pizarro; desde allí no puede sino verse lo sensato e inevitable de la sentencia con la que se condenó a Atahualpa y su mundo. Los cuerpos de las esposas de Atahualpa, las víctimas más visibles, no encarnan la razón; encarnan más bien otro fanatismo violento cuya expresión es el suicidio que seguirá a las exequias del Inca. El cuadro muestra a estas mujeres exhibiendo un dinamismo sinuoso que contrasta con la verticalidad de los otros personajes y la horizontalidad del cuerpo inmóvil del Inca; la uniformidad de sus rostros idealizados, las coincidencias en su vestimenta y el que se les muestre en hilera, las hacen parecer una misma figura detenida en diversos momentos de una secuencia que se inicia cuando encara a un soldado y termina cuando sus súplicas son rechazadas intransigentemente por un fraile.

\footnotetext{
3 López, 1867: 174-175.

4 Poole, 2000: 60.

5 Ibidem: 53.
} 


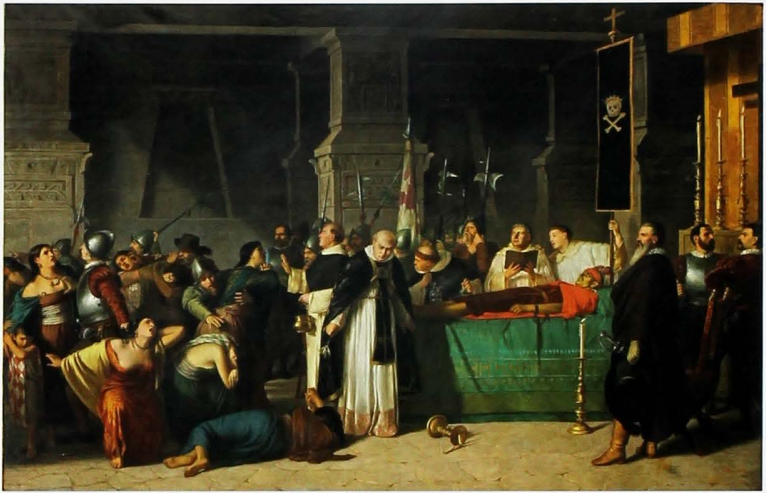

Luis Montero, Los funerales de Atahualpa, 1867. Pinacoteca Municipal Ignacio Merino, Municipalidad de Lima, en custodia en el Museo de Arte de Lima.

Entre un punto y otro, el observador es testigo de su maltrato corporal: es zarandeada y medio desvestida, tirada de los cabellos y forzada a hincarse de rodillas hasta, ocultando su rostro, caer a tierra de manera humillante. En su pintura, Luis Montero parece hacer eco de los autores de la Operática Inca pues no condena a los bárbaros idolatras sino que "pareciera expresar simpatía hacia las Vírgenes del Sol que siguen siendo leales a su dios

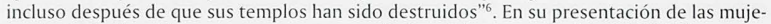
res de Atahualpa, Montero, como ocurre con la Operática Inca a finales del XVIII, "compara el destino del imperio Inca con el destino de las mujeres conquistadas (o violadas)"

A diferencia de los dieciochentistas franceses que escogen como telón de fondo la leyenda negra, Luis Montero opta por visualizar verídicamente la versión de los vencedores que recoge el estadounidense William Prescott en su History of the Conquest of Peru (1847). Un siglo más tarde, Szyszlo optará más bien por la tradición viso-verbal producida desde el punto de vista de los vencidos y seguirá un modelo que encuentra en la yuxtaposición de las muertes de los Incas Atahualpa y Túpac Amaru que el cronista Felipe Guamán Poma de Ayala llevó a cabo en los textos y dibujos de su manuscrito El primer nueva corónica y buen gobierno (1600-1615) ${ }^{8}$. Guamán Poma produjo dos dibujos muy semejantes que buscan crear en el lector la sensación de ser dos veces testigo del mismo desenlace y servir como evidencia de un maltrato del mundo andino que casi no ha cambiado en cincuenta años.

Ambos dibujos presentan una escena dramática que parece repetirse con distintos actores; de manera similar a la Operática Inca, estos encarnan posiciones morales: la violencia de representantes de la corona europea, la superioridad moral de su víctima el Inca y el buen

6 Ibidem: 56 .

7 Ibidem: 67.

8 La edición facsimilar accesible en esos años era Guamán Poma de Ayala. Felipe. 1956. La nueva crónica y buen gobierno, escrita por Don Felipe Guaman Poma de Ayala. Interpretada por Luis Bustios Gálvez. I-III. Lima: Talleres del Servicio de Prensa, Propaganda y Publicaciones Militares. 
sentido del observador-narrador. Tres verdugos barbados de origen europeo se presentan en posturas y actos agresivos: a la izquierda, uno sujeta los pies de la víctima, a la derecha otro le inmoviliza la cabeza y, detrás de la mesa, dando cara al espectador, el tercero sostiene con la mano izquierda un sable sobre el cuello del Inca mientras que su mano derecha está a punto de descargar un golpe de maza sobre el arma con el fin de decapitarlo. La víctima, como en la pintura religiosa europea de la época, muestra en su rostro signos de nobleza y paz interior; las piernas ligeramente flexionadas y las manos sobre el vientre sosteniendo un crucifijo reflejan mansedumbre. La posición del observadornarrador está construida de una manera más compleja y varía de un dibujo a otro: una imagen no incluye una tercera posición, es externa; en la otra, cinco personajes andinos (entre hombres y mujeres) cubiertos por mantos imploran observando la escena. La tercera posición es ocupada aquí tanto por el observador-narrador como el público dentro de la imagen; Guamán Poma, sin embargo, busca que tal posición sea ocupada por el Rey de España, el destinatario final del manuscrito. Esto queda reflejado en los textos que acompañan las imágenes: colocándose expresamente al lado del Rey de España el observador-narrador denuncia a los funcionarios que han transgredido los órdenes universales recibidos de Europa: "Ves aquí como le echa a perder al Emperador con la soberbia, cómo pudo sentenciar un caballero a su rey? Y si no le matara toda la riqueza fuera del Emperador y se descubriera todas las minas." ${ }^{2}$. Los verdugos que llevaban yelmos y armaduras militares en la primera imagen, en la segunda llevan sombreros altos y jubones de cuello escarolado; el paso de coraza militar a ropaje de funcionario colonial sin cambio de actitudes señala que la violencia que se aplicó sin razón durante la conquista se repite innecesariamente. Quienes las llevan a cabo no son personas que siguen las instrucciones del buen gobierno del Rey de España, capaces de reconocer el grado de civilización del Imperio Inca y la nobleza de sus gobernantes, sino individuos llevados por el fanatismo religioso y la ambición personal. Frente a una víctima en la que se subraya un alto estatus moral, el observador busca explicaciones.

Los dibujos de Guamán Poma muestran la drástica separación entre dos órdenes en el Perú de los siglos XVI-XVII; muestran, también, la oportunidad perdida, aunque todavía rescatable, de una continuidad histórica. Paradójicamente, lo hace presentando el transcurrir temporal como una repetición circular. La violencia es una actitud europea; el Inca es mesurado y tolerante, su buen sentido lo lleva a aceptar la cristianización y hacerse vasallo del Rey, en otras palabras, le da la autoridad moral. La posición que debe adoptar el observador es aquella utópica que llama al rescate de lo que todavía puede ser. El relato 
451

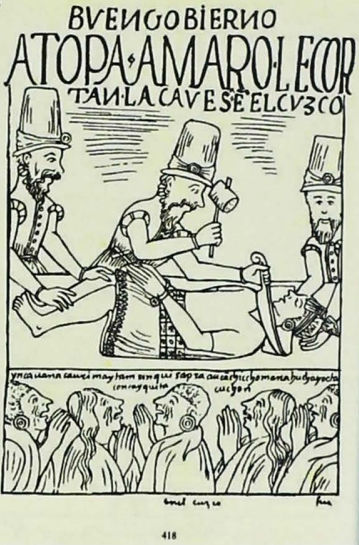

Felipe Guamán Poma de Ayala. Buen Gobierno: atopa amaro le cortan la cavesa en el Cuzco. Dibujo incluido en "El primer nueva corónica y buen gobierno" (1600-1615) de Guamán Poma deja explícitamente de lado las fuentes de narración lineal para adoptar otras, como explica Carmen Martín Rubio, que interpretan la historia como sucesión repetitiva: "en la muerte de Atahualpa: las danzas y leyendas populares hablan de que fue degollado ... y esa es la versión que representa pictóricamente, a pesar de que los cronistas tempranos, e incluso su coetáneo Martín de Murúa, dicen que fue ejecutado mediante garrote"10.

La visualización que Montero lleva a cabo de lo narrado y descrito por Prescott en base a los cronistas del renacimiento tiene una versión verbal contemporánea en el trabajo de Ricardo Palma. Atahualpa es uno de los personajes de "Los Incas ajedrecistas" (1910) en su última serie de Tradiciones peruanas, el otro es Manco Inca. Palma presenta a Atahualpa y Alonso de Riquelme encarnando dos posiciones radicales y enfrentadas; una posición intermedia, tolerante y sensata, es encarnada por Hernando de Soto. A pesar de ser Atahualpa la víctima final de

la violencia, el relato busca que se tome la posición de de Soto quien, al tratar "de igual a igual" al Inca, deja vislumbrar la posibilidad perdida y utópica de lo que pudo haber sido un futuro de colaboración mutua. Ambiguamente, Palma coloca en esta posición moral también a Pizarro, quien, como lo hace aparecer Montero, se muestra como una figura imparcial convocando al consejo que decide por mayoría la ejecución. Tanto el resultado conocido como la posibilidad utópica se apoyan, sin embargo, en un devenir histórico lineal. La fatalidad de la Operática Inca tardía es aplicada al relato sobre Manco Inca, padre de Túpac Amaru. En este caso, la intransigencia española, encarnada en el soldado Gómez Pérez, y la reacción violenta de Manco Inca dan como resultado la muerte de ambos y el indiscutible e inevitable fin del orden andino. La posición intermedia ha sido aquí eliminada; cuando se llega a este momento histórico el fin del orden nativo es algo ya consumado, como imposible es la utopía de un Inca aespañolado ${ }^{11}$. Pese a sus grandes diferencias, entre la versión de Guamán Poma y la de Palma hay sin embargo dos elementos en común relacionados a la manera no lineal de ver la historia: Palma yuxtapone la muerte de dos Incas creando una narrativa que se repite -su "estaba escrito"12 confirma las expectativas- y asegura que su relato se basa en la tradición popular.

"Los Incas ajedrecistas" es uno de un puñado de relatos que Palma dedica al incanato, los otros son "Palla Huarcuna" (1860), publicado en 1872, cuatro años después de la exhibición de Montero en Lima, y "La gruta de las maravillas" y "La achirana del Inca", aparecidas

10 Martín Rubio, 2008: 120.

11 Palma, 1977: 428.

12 Ibidem: 428 . 
ambas en 1875 como parte de la tercera serie de tradiciones. Estos tres textos comparten patrones significativos. "Palla Huarcuna" tiene en común con la segunda la conversión en piedra de algunos de sus personajes, y con la última una historia de amor. A pesar de los vínculos que se pueden establecer entre la relación triangular de estos amores y la Operática Inca, el patrón más significativo para los fines de este ensayo está en que cada uno de estos relatos presenta como personaje a un Inca viajero (Túpac-Yupanqui, MaytaCápac y Pachacutec, respectivamente) que a su paso lleva a cabo acciones transformadoras que superan todos los obstáculos naturales. "[Para él] nada había imposible"13 nos dice el narrador de "La gruta de las maravillas" refiriéndose a Mayta-Capac, constructor de una calzada de piedra de tres leguas de largo y un gran puente colgante; "[G]rande eres y para ti no hay imposible" 14 le dice la doncella de "La achirana del Inca" al Pachacutec que ordena a cuarenta mil hombres que desvíen el cauce de un río. Esta visión no constituye la mera expresión de la perspectiva personal de Palma, responde a una idea del tiempo incaico contemporáneamente compartida por muchos, entre los que se encuentra el ya citado Vicente Fidel López: "Un día antes del día de la tragedia de Caxamarca, Attabaliba era el Rey más poderoso y más opulento del orbe; y sus pueblos eran de los más civilizados de la tierra"15.

125 años después de publicada "Palla Huarcuna", en su libro Buscando un Inca, el historiador Alberto Flores Galindo discute una encuesta a jóvenes limeños de sectores adinerados y pauperizados que revelaría el proceso de formación y establecimiento de lo que llama una "utopía mesiánica andina". La visión que en 1860 muestra un incanato de personajes heroicos, expansión, transformación del ambiente natural y omnipotencia, se ha convertido para 1985 en un periodo histórico concreto en que la sociedad era organizada de manera justa y armónica ${ }^{16}$. Tal utopía, elaborada colectivamente a partir del siglo XVI, contribuye a que la visión que en el siglo XX se tiene del imperio incaico se constituya en "un paradigma para el mundo actual"17; es decir, en una valoración del pasado que lo convierte en una imagen invertida de la realidad del país y lo proyecta como futuro posible. Para Flores Galindo, tal mesianismo apunta a "doblegar tanto a la dependencia como a la fragmentación"18 a la que se ha visto sometida la población de los Andes y consiste en "una apropiación de formas traídas por los dominadores a las que los vencidos dan contenido propio"19. Entre tales contenidos, Flores Galindo identifica el relato de "Inkarri" (fusión de "Inca" y "Rey"), una narración constituida por una serie o ciclo de relatos interrelacionados que "se articulan", como afirma Flores Galindo, "con otras manifestaciones de la cultura popular andina" ${ }^{20}$ que incluyen relatos poshispánicos (con elementos históricos tales como el encuentro entre los soldados españoles y la corte de Atahualpa, la captura de este último y su muerte) y literatura oral (como el poema anónimo Apu Inca Atawallpaman, y los relatos acerca de Con Tici Viracocha, Curinaya Viracocha, y Adaneva). Arguyo que tanto en estos relatos como en las Tradiciones de Palma, se presenta una historia no lineal sino recurrente, y se incluye allí la figura de un caminante andino capaz de acciones sobrehumanas. La mayoría de las versiones de Inkarrí también presentan a este personaje en movimiento como un héroe cultural que, siendo similar pero más fuerte que otros hombres, recorre el mundo, forma un ejército, y ordena las piedras del paisaje haciéndolas caminar. Así es como Inkarrí aparece también como fundador de lugares y poblaciones. Llevado a un

13 Palma, 1894: 10.

14 Ibidem: 11.

15 López, 1867: 174.

16 Flores Galindo, 1988: 21.

17 Ibidem: 21

18 Ibidem: 19.

19 Ibidem: 70-71

20 Ibidem: 23. 
enfrentamiento con su hermano, o un rival semejante (como lo sería el Rey de España), es muerto y decapitado. Separada del cuerpo, su cabeza es enterrada en un lugar lejano. Los relatos concluyen mencionando la posibilidad de que Inkarrí retorne por medio de un reintegro físico que ocurriría con la regeneración de su cuerpo desde la cabeza hasta los pies ${ }^{21}$.

Según el historiador Franklin Pease ${ }^{22}$, el ciclo de Inkarrí habría empezado en la memoria popular para inicios del siglo XVII. Entre los elementos históricos que el ciclo aglutinaría se encuentran las pérdidas de Atahualpa y de Túpac Amaru. "Incarrí [sic]", dice por su parte Flores Galindo, "resulta del encuentro entre el acontecimiento -la muerte pública de Túpac Amaru I- con el discurso cristiano sobre el cuerpo místico de la iglesia y las tradiciones populares."23. Para principios del siglo XVII, las ilustraciones de Guamán Poma evidencian una memoria colectiva en la que se ha producido la superposición de ambas ejecuciones, en donde lo más significativo es el desplazamiento retrospectivo de la decapitación de Túpac Amaru a la ejecución de Atahualpa. Si bien parece ser cierto, como señala Hiroyasu Tomoeda, que la primera versión registrada de la serie de Inkarrí data de 1951, su difusión contemporánea se debe mayormente al antropólogo y escritor José María Arguedas, quien recogió en 1956 lo que por muchos años fue la primera versión conocida ${ }^{24}$. En general, cuando se habla de la recopilación y difusión del ciclo, los críticos se refieren a las versiones recogidas entre 1953 y 1972 . La primera de estas fechas es también el año de la traducción al español que lleva a cabo Arguedas del Apu Inca Atawuallpaman. El bilingüismo y su formación literaria y antropológica colocarán a Arguedas en un lugar clave en este proceso de difusión y también lo convertirán en mediador entre la población andina anónima y los intelectuales y artistas. Arguedas incluirá en su propio trabajo creativo algunas de las estructuras simbólicas y narrativas de estas series. Publicada en 1964, su novela Todas las sangres, ubicada en los Andes, ofrece un final abierto teniendo como telón de fondo el amenazante ruido sordo y creciente de un río subterráneo.

Críticos como Tomoeda han cuestionado el concepto del mesianismo andino señalando que si bien es cierto que relatos indígenas como los de Inkarrí incluyen la posibilidad del regreso del Inca-Rey, este aspecto no es el central en las versiones recogidas originalmente por Arguedas ni en sus comentarios personales tempranos. Arguedas no llama la atención sobre el mesianismo sino hasta 1964, año de la publicación de Todas las sangres. Tomoeda arguye que el énfasis en lo mesiánico fue puesto años después por los intelectuales y artistas, incluyendo aquí al Arguedas de 1964; esto revelaría que lo mesiánico en el caminante andino no es parte del discurso indígena sino más bien de un discurso "indigenista" 25 . Flores Galindo, por otro lado, reconoce implícitamente este hecho en Buscando un Inca, y sugiere indirectamente las razones para ello. "Los intelectuales", dice "leyeron en el mito el anuncio de una revolución violenta" ${ }^{26}$. Entre estos intelectuales y artistas a los que Flores Galindo se refiere se encuentra Fernando de Szyszlo. Vinculado a Arguedas desde los inicios de su carrera, Szyszlo va a utilizar como fuente plástica la traducción arguediana del Apu Inca para llevar a cabo su exposición de 1963; para esa fecha, las movilizaciones campesinas, en particular aquellas en el valle de La Convención, en el Cuzco, daban cuenta de la violencia.

La idea de Inkarrí no está presente en los primeros cuadros de Szyszlo de tema Inca. El tema de la muerte de Atahualpa aparece implícito en el título Cajamarca de 1962; éste

21 Arguedas, 1956.

22 Flores Galindo, 1988: 48.

23 Ibidem: 48.

24 Arguedas, 1956.

25 Tomoeda, 2006: 168.

26 Flores Galindo, 1988: 24. 
define una localidad y un escenario histórico y establece referencias remotas con las tradiciones escrita y oral. Formalmente Szyszlo ha "desestabilizado" visualmente formas geométricas y planos de colores que venía explorando de manera cubista y luego abstracta durante los años cincuenta. Lo que en cuadros sin título anteriores a ese año eran líneas curvas y rectas intersecadas entre sí formando superficies de colorido intercalado, pasa a ser luego imprecisos planos irregulares, bandas arqueadas, corvos y zonas de achurado angular que aparecen en proximidad o yuxtapuestos a discos y volúmenes fragmentados. Szyszlo llega a determinar aquí aquello que Rosalind Krauss llama "ambientes"27 refiriéndose a la pintura de Jackson Pollock; es decir, la sensación de densidad y de un fondo a lo lejos producidos tanto por los brochazos y empastes que han eliminado previas insinuaciones de líneas, y dejan en su lugar textura, como por veladuras que cubren parcialmente formas de contorno impreciso. Dentro de este "sitio", Szyszlo crea formas que buscan desencadenar percepciones espaciales y cinéticas; la manera en que quedan vinculadas a una narrativa es un proceso que decidirá el futuro de su obra. En Cajamarca, la narrativa de la que se depende es demasiado vasta como para poder establecer con propiedad los contenidos a los que se refieren las imágenes; en la práctica, dejarán sentados los parámetros para una mayor elaboración futura. Con el Apu Inca Atawallpaman se llega a lo que Richard Dorment denomina, también en relación a Pollock, "violencia y tragedia" 28 . La serie no trae formas totalmente nuevas, más bien expande y articula del vocabulario visual encontrado y elaborado en Cajamarca; el escenario es el mismo, lo que ha "evolucionado" es la tensión dramática. Veladuras y empastes buscan producir la ilusión de estar observando un espacio tridimensional con las propiedades del líquido en movimiento; lo que eran planos dan la impresión de ser volúmenes. Las formas que predominan en Cajamarca y el Apu Inka siguen patrones como el agrupamiento, la inestabilidad, la multidireccionalidad, la interrupción; en el segundo, gracias a los contenidos verbales brindados por el poema, Szyszlo los asociará a acciones de relatos de batalla: golpes, cortes, perforaciones, agresión, defensa. Dramáticamente, esto crea agentes, agresores y víctimas. El expresionismo abstracto, sin embargo, habría surgido, según afirma Timothy Clark en su ensayo “Jackson Pollock's Abstraction" (1990) para configurar la subjetividad, los dramas internos:

Lo que Pollock inventó en 1947-50 fue un conjunto de formas en las que aspectos previamente desorganizados de la auto-representación -lo inefable, lo somático, lo salvaje, lo aventurado, espontáneo, incontrolado, 'existencial', el 'más allá' o 'anterior' a las actividades conscientes de la mente- pudieron conseguirse un conjunto relativamente estable de significantes. Una línea vertida con salpicaduras equivale ahora a espontaneidad, etc. Cierto tipo de entrelazamiento pintado puede ahora asumirse -muy por casualidad-representando estados mentales como la ira o la euforia ${ }^{29}$.

Si bien puede argüirse que Szyszlo hace uso de esta gramática para asignar contenidos emocionales nacionalistas a formas semejantes a las codificadas por Pollock, también debe tenerse en cuenta el problema de que éstas implican agentes en cada extremo de las acciones. La serie del Apu Inka trae un juego claro de círculos y anillos rotos, de rojos y negros que tienen como referente procesos como el sangrado, acciones como la decapitación y distancias como la profundidad abisal. Los volúmenes deben ser entendidos como cuerpos o sombras de las víctimas, y el cinetismo de los ángulos y curvaturas como el rastro de los agresores. Hay, sin embargo, una tercera arista en este juego de tensiones: el narrador, quien paradójicamente identifica lo incontrolable de sus propios procesos mentales con

27 Citada en Kent, 1999: 23. [Mi traducción del inglés].

28 Dorment, 1999: 17. [Mi traducción del inglés].

29 Clark, 1990: 180. [Mi traducción del inglés]. 
aquellos de los participantes. Compartiendo su espacio se encuentra el observador, quien debe sentirse inmerso en el escenario y tan cercano emotivamente que pueda tener la impresión táctil de ser parte de la violencia del trauma. A pesar de la casi virtual ausencia de agresores se busca la empatía con la víctima, no necesariamente la reflexión crítica.

¿Por qué en ese momento y de esa manera Szyszlo asume tal posición frente a la historia del Perú? Críticos como Mirko Lauer y Alfonso Castrillón lo explican como una afirmación y defensa reformista de intereses de clase que eran respuesta a la violencia de las movilizaciones populares y la resistencia latifundista de las décadas anteriores. Otra respuesta puede encontrase en la explicación de Clark a la aparición del expresionismo en los Estados Unidos de los años cincuenta:

Estos [los desorganizados de la auto-representación] son aspectos de la experiencia que la cultura quiere representada ahora, de la que quiere hacer uso, porque el capitalismo en cierta etapa de su desarrollo necesita cuentas más convincentes de lo corporal, lo sensual, lo 'libre', para así poder extender -quizá perfeccionar- su colonización de la vida cotidiana ${ }^{30}$.

Los sesenta pudieron ser muy bien el ahora de tal modernización capitalista en el Perú. Szyszlo no solo produce formas sino que también entrena a su público en la recepción y entendimiento crítico del arte moderno; esto le permitirá ser "comprendido", y también que una clase media extendiera su "colonización" de lo irracional andino que incluiría masivos movimientos de población. Con las series La ejecución de Túpac Amaru e Inkarrí, Szyszlo incrementará a su lenguaje de los círculos truncados y anillos, aparecidos anteriormente, formas neofigurativas de círculos pequeños en racimos, cuerpos totémicos, colmillos, y alusiones oculares y dentadas. El artista se hace, además, de las estructuras dramático narrativas del caminante mesiánico tanto yuxtaponiendo la muerte de Túpac

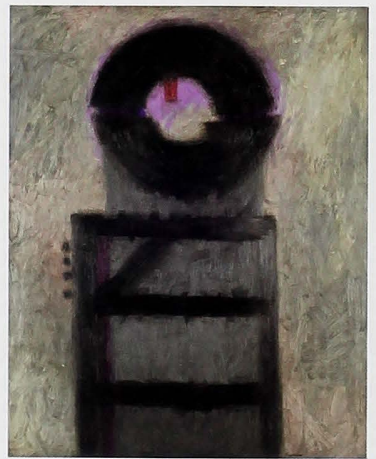

Fernando De Szyszlo, La ejecución de Típac Amaru

$X, 1966$. Colección Museo de Arte Contemporáneo Lima. Fotografia: Juan Pablo Murrugarra.
Amaru a la de Atahualpa como presentando formas que debían leerse como cabezas separadas de sus cuerpos.

El vínculo de la última de estas series con el relato mitológico de Inkarrí produce un cambio en la posición del espectador. Recurrir a la lengua quechuas, presentar particulares eventos en orden cronológico y repetir con variantes patrones dramáticonarrativos de la tradición oral andina, al margen del uso del color y de iconografía precolombina, le servirían a Szyszlo para atar lo que llama "hilos rotos en la historia de nuestras identidades" ${ }^{31}$; es decir, de ofrecer una continuidad "peruana" en el tiempo basada no en una secuencia histórica causal que incluye una ruptura insalvable, sino en la repetición actualizada de una manera cumulativa de entender el universo y la vida social. La posición del observador consistiría en enfrentar críticamente la ideología de una pintura como la de Montero; no

30 Ibidem: 180. [Mi traducción del inglés].

31 Lauer, 1975:16. 
necesariamente dirigiéndose a juzgar las acciones de los invasores europeos o de sus representantes, sino a cuestionar su manera de contar la historia y concebir protagonistas, de imaginar el futuro y de justificar el resultado de su proyecto de construcción nacional.

La producción en 1969 de la serie Valle Grande convierte al Che Guevara en la última encarnación del heroico caminante andino y, por extensión, en el último Inca; propone, además, que la manera no lineal de entender el pasado nacional sea aplicada también a toda el área cultural de los Andes e incluso a toda Latinoamérica. Podría arguiirse que la elección del Che como encarnación de este héroe pudo haber sido una respuesta de clase a la violencia revolucionaria continental, puesto que así como "exporta" el modelo mítico de narrativa nacional también absorbe y neutraliza la narrativa particular de un individuo y su potencial revolucionario. Quedaría, sin embargo, por responder la pregunta de cómo es que este modelo se hace funcional en países como Cuba, de circunstancia tan diversa. Cuando aparece Valle Grande, el modelo mesiánico de caminante heroico ya era utilizado en la isla caribeña; en febrero de 1968, en el ensayo "Ernesto Guevara, comandante
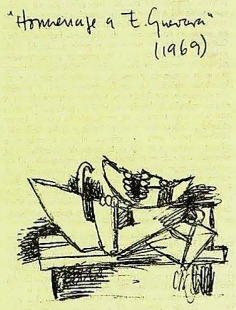

Fernando de Szyszlo. Homenaje a Ernesto Guevara. Dibujo incluido en el libro "Szyszlo: indagación y collage" (1975). Editado por Mirko Lauer. nuestro", José Lezama Lima afirma:

Las citas con Túpac Amaru, las charreteras bolivarianas sobre la plata del Potosí, le despertaron los comienzos, la fiebre, los secretos de ir quedándose para siempre. Quiso hacer de los Andes deshabitados, la casa de los secretos. Lo que se ocultaba y se dejaba ver era nada menos que el sol, rodeado de medialunas incaicas ... El medialunero Viracocha transformando las piedras en guerreros y los guerreros en piedras. ... Nuevo Viracocha, de él [el Che] se esperaban todas las saetas de la posibilidad y ahora se esperan todos los prodigios en la ensoñación. ... [Tuvo la areteia.] El sacrificarse en la pirámide funeral, pero antes dio las pruebas terribles de su tamaño para la transfiguración ${ }^{32}$.

Lezama, criticado en Cuba por su supuesta estética burguesa, no sólo incluye en el texto la idea de un personaje viajero andino y la del dios-soberano de omnipotencia transformadora de la naturaleza, sino que allí también establece vínculos entre las figuras (que coloco en orden cronológico) de Viracocha, Túpac Amaru y el Che Guevara, mientras le concede mítica y contemporáneamente a Guevara (ejecutado y mutilado en octubre de 1967) la capacidad de retorno. En su labor de difusión de la cultura andina, Arguedas llegó en enero de 1968 de visita a La Habana y dio una conferencia sobre Inkarrí, "Los mitos quechuas posthispánicos", el texto se publicó allí en abril ${ }^{33}$. Había aparecido antes, a fines de $1967^{34}$, sin embargo, en la revista Amaru de Lima. Existe además, una aparente versión del héroe cultural andino presentada por un personaje más radical, el francés Regis Debray, quien declara desde una cárcel boliviana en una entrevista publicada en agosto: "El Che fue un Cristo moderno" 35 , para agregar luego "tenía la misma concepción de la muerte que Fidel o Martí. Es decir, la muerte como promesa del renacimiento, La muerte como una suerte de

32 Lezama Lima, 1997: 229-230.

33 José María Arguedas, 1968. "Los mitos quechuas posthispánicos" Casa de las Américas 47. (La Habana marzo-abril).

34 José María Arguedas, 1967. "Mitos quechuas pos-hispánicos". Amaru 3 (octubre-diciembre): 14-18.

35 Nadle 1968: 40. [Mi traducción del inglés]. 


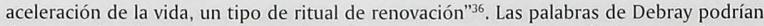
demostrar la existencia contemporánea de un contexto cristiano mesiánico que subyace a la narrativa revolucionaria de esa década.

Con el golpe de estado de octubre de ese año en el Perú, arguye Alfonso Castrillón, el pensamiento "populobelaundista" se desmorona y con éste el proyecto de Szyszlo: "El programa de reformas del 68 releva al artista y la acometida ideológica inhibe su ideología: las formas de Szyszlo han quedado deshabitadas de los contenidos del 63" 37 . El estado pasó a controlar y prácticamente se apropió de aquel tipo de discurso nacionalista. En junio de $1969^{38}$, adoptará a Túpac Amaru II (José Gabriel Condorcanqui) como figura narrativa de la reforma agraria y en 1970 usará su retrato como imagen oficial tornando en logotipo un diseño Pop Art del artista Jesús Ruiz Durand (1940). Entre 1973 y 1974, bajo la dirección de Héctor Béjar, ex militante en las guerrillas de 1965, el estado llevará a cabo 978 "Encuentros Inkari" transportando masivamente grupos selectos entre los habitantes de provincia ${ }^{39}$; los eventos, que incluían actividades folklóricas, artesanales, artísticas y deportivas, buscaban la reintegración metafórica del Inka. Para 1975, con la premiación nacional del retablista Joaquín López Antay, las artes populares amenazaron desplazar a la pintura moderna.

Las series de Szyszlo que he discutido logran monopolizar pictóricamente el tema del cuadro de Montero durante los sesenta. Este pasó a ser, en teoría, una representación del momento en que se inicia, o reinicia, un ciclo más en una historia peruana recurrente, momento igualmente representado por el dibujo de Guamán Poma y por la serie Apu Inka. El dibujo de Guamán Poma y la serie de Szyszlo dedicados a Túpac Amaru representarían, por su parte, acciones rituales que en el pasado han puesto en evidencia la temporalidad circular andina. La serie Inkarrí, no solo se apoya en la narrativa sino también en el aparato teórico-crítico que acompaña al mito. La serie dedicada al Che yuxtapone la narrativa de desmembramiento del Inca a la teoría de los focos guerrilleros, la figura del caminante andino a la del guerrillero heroico, y da pie para interpretar cada levantamiento sociopolítico en el continente como resultado del proceso de reintegración de un cuerpo de dimensiones continentales. En 1969, Arguedas mismo asocia los movimientos campesinos con la figura de la guerrilla en carta al dirigente de La Convención Hugo Blanco: "Yo vi tu retrato en una librería del barrio latino de París; me erguí de alegría, viéndote junto a Camilo Cienfuegos y al "Che" Guevara" 40 . Los alcances fuera del Perú de este modelo mesiánico, que Arguedas parece haber contribuido a crear, requieren mayor exploración. En particular si se observa que en el siglo XXI la representación visual mesiánica del guerrillero Guevara se ha incrementado presentándolo no solo como un Cristo revolucionario, sino también como un caminante que atraviesa a pie la agreste naturaleza americana para cambiar un mundo y seguir siendo ejecutado, mutilado y enterrado en medio de los Andes.

\footnotetext{
36 Ibidem: 42. [Mi traducción del inglés].

37 Castrillón, 1980: 82.

38 Lituma Agüero, 2011: 57.

39 Franco, 1983: 705.

40 Blanco y Arguedas, 1969: 13-14.
} 


\section{Bibliografia}

Arguedas, José María

1956 "Puquio: una cultura en proceso de cambio". Revista del Museo Nacional XXV: 184-232.

Blanco, Hugo; Arguedas, José María

"Correspondencia". Amaru 11:12-15.

\section{Castrillón, Alfonso}

1980 "Syszlo frente a la crítica". Hueso Húmero 5-6: 77-87.

Clark, Timothy

1990 “Jackson Pollock's Abstraction”. En Reconstructing Modernism: Art in New York, Paris, and Montreal, 1945-1964. Serge Grimbault (Ed.): 172-231. Cambridge: MIT Press.

Dorment, Richard

1999 "The Radiant Side of Jack the Dripper". The Daily Telegraph (Marzo 10): 17.

\section{Flores Galindo, Alberto}

1988 Buscando un Inca. Lima: Editorial Horizonte.

\section{Franco, Carlos}

1983 "SINAMOS y la promoción de la participación" En El Perú de Velasco. Tomo 3: 681-708. Lima: CEDEP.

\section{Guamán Poma de Ayala, Felipe}

1980 El primer nueva corónica y buen gobierno. México: Siglo XXI.

\section{Kent, Sarah}

1999 "Splash It All over" Time Out (Marzo 10. 17): $22-24$

\section{Lauer, Mirko}

1975 Szyszlo: indagación y collage. Lima: Mosca Azul.
Lezama Lima, José

1997 "Ernesto Guevara, comandante nuestro". En Ensayos latinoamericanos: 229-230. México: Agencia Literaria Latinoamericana.

\section{Lituma Agüiero, Leopoldo}

2011 El verdadero rostro de Túpac Amaru (Perú, 1969-1975). Lima: UNMSM y Pakarina Ediciones.

López, Vicente Fidel

1867 "Los funerales de Atahuallpa (Pintura original de don Luis Montero)". La Revista de Buenos Aires 53: 160-176. Buenos Aires.

Martín Rubio, Carmen

2008 "La muerte de Tupac Amaro, según las ilustraciones de Guamán Poma de Ayala" Investigaciones sociales 20: 115-128. Lima.

Nadle, Marlene

1968 "Regis Debray Speaks from Prison" Ramparts Magazine (Agosto): 40-42.

Palma, Ricardo

1894 Tradiciones peruanas. Tercera serie. Tomo II. Barcelona: Montaner y Simón.

-.-. 1977 Cien tradiciones peruanas. Caracas: Biblioteca Ayacucho.

Poole, Deborah

2000 Visión, raza y modernidad. Lima: Sur.

\section{Tomoeda, Hiroyasu}

2006 "Inkarrí en La Habana: discurso indigenista en torno a un mito indígena". En Desde el exterior: el Perú y sus estudiosos. Luis millones et Akahiro Kato (Edits.): 167-188. Lima: UNMSM. 


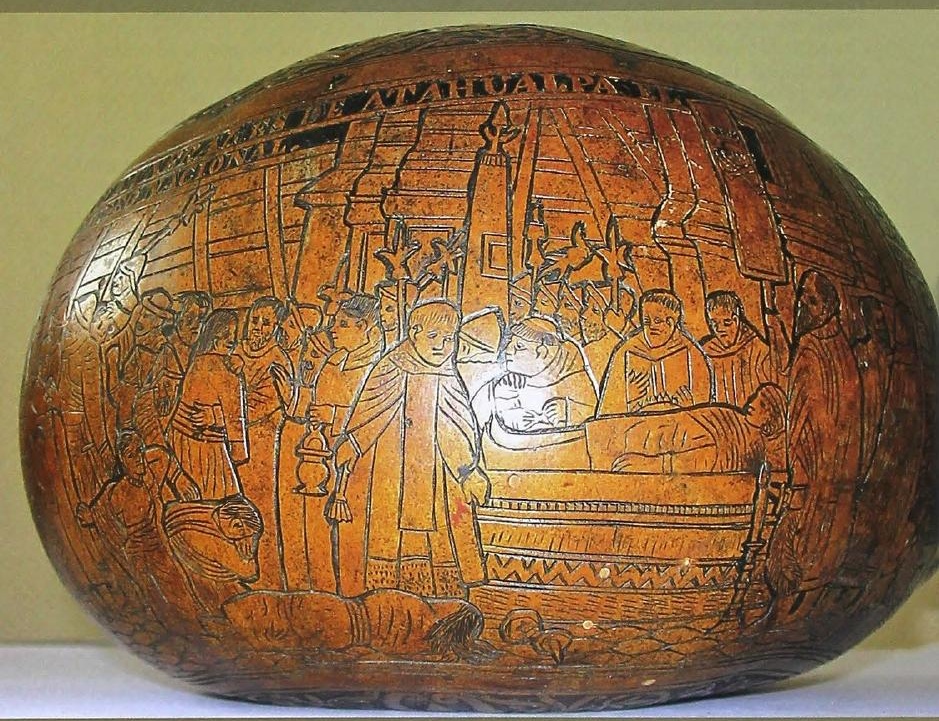

Azucarero Los fumeroles de Afahualpa. Colección Museo Nacional de la Cultura Peruana. 